$\begin{array}{cl}\begin{array}{cl}\text { Revue } \\ \text { de /histoire }\end{array} & \text { Revue de l'histoire des religions } \\ \text { des religions } & \begin{array}{l}\mathbf{4} \mathbf{2 0 0 7} \\ \text { Varia }\end{array}\end{array}$

\title{
Les dernières communautés chrétiennes autochtones d'Afrique du Nord
}

The last native Christian communities of North Africa

\section{Virginie Prevost}

\section{(2) OpenEdition}

Journals

Édition électronique

URL : http://journals.openedition.org/rhr/5401

DOI : 10.4000/rhr.5401

ISSN : 2105-2573

Éditeur

Armand Colin

Édition imprimée

Date de publication : 1 décembre 2007

Pagination : 461-483

ISBN : 978-2200-92335-8

ISSN : 0035-1423

Référence électronique

Virginie Prevost, "Les dernières communautés chrétiennes autochtones d'Afrique du Nord », Revue de I'histoire des religions [En ligne], 4 | 2007, mis en ligne le 01 décembre 2010, consulté le 14 novembre 2019. URL : http://journals.openedition.org/rhr/5401 ; DOI : 10.4000/rhr.5401 


\title{
Les dernières communautés chrétiennes autochtones d'Afrique du Nord
}

\begin{abstract}
Pendant plusieurs siècles après la conquête arabe, des communautés de chrétiens autochtones se sont maintenues dans le Sud tunisien, sans bénéficier d'apports extérieurs venus raviver leur foi. Les oasis du Djérid et du Nafzâwa, dominées par les musulmans ibadites, ont certainement constitué la dernière retraite de ces chrétiens nord-africains. De nombreux historiens contemporains considèrent qu'ils ont pu subsister jusqu'au XIV et parfois même jusqu'au XVIII siècle. L'analyse des sources arabes sur lesquelles ils se fondent démontre que ces textes ne fournissent aucune preuve de leur extrême longévité. Il est bien plus probable que les chrétiens ont disparu des oasis vers le milieu du XIII siècle, en même temps que les ibadites auquel leur sort a été fortement lié.
\end{abstract}

\section{The last native Christian communities of North Africa}

For several centuries after the Arab conquest, some communities of native Christians remained in the southern part of Tunisia, without receiving external assistance to revive their faith. The oases of Jarîd and Nafzâwa, controlled by Ibadite Muslims, certainly constitued the last refuge for those North-African Christians. Many contemporary historians consider that they could live on until the $14^{\text {th }}$ or even until the $18^{\text {th }}$ century. The analysis of the Arabic sources they interpret shows that those texts do not give any evidence of such an extreme longevity. It is more than likely that the Christians disappeared from the oases about the middle of the $13^{\text {th }}$ century, at the same time as the Ibadites to which their fate was closely related. 
Le Sud tunisien est connu pour avoir conservé, des siècles après la conquête arabe, des communautés de chrétiens autochtones qui se sont maintenues aux côtés des musulmans, sans bénéficier d'apports extérieurs venus raviver leur foi. C'est le cas à Gabès et à Gafsa, et surtout dans les deux groupes d'oasis, le Djérid ou la Qasțîliya au nord de la grande sebkha, le Nafzâwa au sud de celle-ci. Ces oasis ont certainement accueilli la dernière trace connue du christianisme nord-africain ${ }^{1}$. Toutefois, l'époque de la disparition de ces derniers chrétiens, placée par certains historiens au XIV ${ }^{\mathrm{e}}$ siècle, parfois même au XVIII ${ }^{\mathrm{e}}$ siècle, nécessite d'être revue.

\section{LA CONQUÊTE ARABE}

La tradition chrétienne est fortement ancrée dans le Sud tunisien : ainsi, au ve siècle, les quatre oasis principales du Djérid sont toutes des évêchés ${ }^{2}$. Le sud de la sebkha est sans doute encore majoritairement païen à cette époque, bien que le Nafzâwa compte au moins une ville épiscopale, Turris Tamalleni ${ }^{3}$. Si la foi des populations berbères faiblit probablement pendant le siècle vandale, la conquête byzantine de 533 marque une renaissance chrétienne. Les oasis du Djérid sont sans doute touchées par la grande campagne de christianisation ordonnée par l'empereur, visant à refidéliser les anciens

1. Voir notamment Xavier de Planhol, Minorités en Islam. Géographie politique et sociale, Paris, Flammarion, 1997, p. 201. Mohamed Talbi, «Le christianisme maghrébin de la conquête musulmane à sa disparition, une tentative d'explication », in M. Gervers and R.J. Bikhazi (éd.), Conversion and Continuity: Indigenous Communities in Islamic Lands, Toronto, Pontifical Institute of Mediaeval Studies, 1990, p. 344-345, croit pour sa part à la survivance de chrétiens indigènes à Tunis à la fin du XIV ${ }^{e}$ siècle en se fondant sur un texte d'al-Burzulî.

2. Pol Trousset, «Les limites sud de la réoccupation byzantine », Antiquité tardive, 10 (2002), p. 149, qui cite les listes d'évêchés de 411 et de 484. Deux évêques sont célèbres, Asellicus de Tozeur qui correspondit avec saint Augustin au sujet des judaïsants et Laetus de Nefta qui périt en martyr lors de la persécution du souverain vandale Hunéric. Joseph Mesnage, L'Afrique chrétienne, évêchés et ruines antiques, Paris, Ernest Leroux, 1912, p. 125 et p. 163.

3. J. Mesnage, «Le christianisme en Afrique, origines, développements, extension », Revue Africaine, LVII (1913), p. 540 et p. 544. 
évêchés romains ${ }^{4}$. Avant que les premières razzias arabes ne surviennent, en tout cas, la région semble fortement christianisée. Les évêques de Gafsa, de Gabès et du Nafzâwa sont présents au concile de $646^{5}$ et il est probable qu'il y a toujours un ou plusieurs évêchés dans le Djérid.

Vers 698, après que les oasiens ont subi pendant plusieurs décennies les expéditions successives menées par les troupes arabes, le général Ḥassân ibn al-Nu 'mân soumet Gabès, Gafsa, la Qasṭ̂liya et le Nafzâwa avec facilité, dans certains cas manifestement à la demande de leurs populations ${ }^{6}$, avant de conquérir définitivement l'Ifrîqiya. On ignore dans quelle proportion les chrétiens des oasis choisissent d'adopter l'islam. La conversion présente un indéniable intérêt pécuniaire puisqu'elle évite le paiement de la djizya, l'impôt de capitation dû par les non-musulmans. Elle laisse également entrevoir l'espoir d'une paix bien méritée après des années de troubles. Les Berbères chrétiens, sans doute lassés par les incessantes querelles dogmatiques des Byzantins, semblent montrer une affinité pour l'islam, liée peut-être à la clarté du message coranique. Ils n'ont plus qu'un faible encadrement clérical et le christianisme qui malgré tout subsiste doit plutôt s'apparenter à « un monothéisme abstrait pouvant se satisfaire de n'importe quel dogme $»^{7}$. Seules deux sources tardives - et contradictoires - abordent la question de la conversion des habitants du Djérid. Au xII ${ }^{\mathrm{e}}$ siècle, le Kitâb alIstibșâr laisse croire à une conversion massive en affirmant qu'à l'arrivée des musulmans, la plupart des habitants se sont convertis à

4. Il paraît désormais acquis que les Byzantins ont étendu leur reconquête jusqu'au Djérid. P. Trousset, op. cit., p. 149-150.

5. Pierre Champetier, « Les conciles africains durant la période byzantine », Revue Africaine, XCV (1951), p. 106.

6. Deux historiens précisent que lorsque Hassân gagne l'Ifrîqiya, trois cents chrétiens viennent au devant de lui pour implorer son aide contre la Kâhina, à cause des saccages dont ils ont été les victimes. Al-Raqîq, Ta'rîkh Ifrîqiya wa-l-Maghrib, éd. al-Zaydân et Mûsâ, Beyrouth, Dâr al-gharb al-islâmî, 1990, p. 31 ; al-Mâlikî, Riyậ al-nufûs, éd. al-Bakkûsh, Beyrouth, Dâr al-gharb al-islâmî, 1983, I, p. 53. Ibn al-Athîr, Al-Kâmil fî l-ta'rîkh, éd. J. Tornberg, Beyrouth, Dâr Șâdir, 1982, IV, p. 371 indique qu'il s'agit de Rûm.

7. Abdallah Laroui, L'histoire du Maghreb. Un essai de synthèse, Casablanca, Centre Culturel Arabe, 1995, p. 73. 
l'islam pour conserver leurs biens. Il ajoute qu'après la conquête, les Rûm/Byzantins furent forcés d'émigrer «à l'exception de ceux qui se sont convertis à l'islam, qui sont restés dans leur région et ont conservé leurs biens, comme les habitants de la Qastîliya et d'autres régions $»^{8}$. Reprenant, au début du XIv e siècle, le même passage, al-Tidjânî remarque que les Ifrîqiyens ont fui, sauf ceux qui se sont convertis ou ceux qui se sont acquittés de la djizya comme les habitants du Djérid ${ }^{9}$. Malgré ce qu'avance le Kitâb al-Istibṣâr, la remarquable longévité de la communauté chrétienne dans les oasis permet de supposer qu'une grande majorité des sédentaires romanisés ont préféré conserver leur foi. À l'inverse, les Berbères nomadisant dans la région, qui étaient sans doute en voie de christianisation ${ }^{10}$ à l'arrivée des Arabes, ont certainement adopté momentanément la religion des conquérants avant d'adhérer, avec force, au mouvement khâridjite.

\section{Chrétiens et ibadites}

À l'issue de la conquête arabe, d'importantes communautés de chrétiens et de juifs subsistent dans l'ensemble du Maghreb. Ces dhimmî ou tributaires ne doivent en rien gêner les dirigeants arabes, qui trouvent là des rentrées d'argent supplémentaires et profitent à l'occasion de leurs compétences. Jusqu'au règne des Almohades, accusés d'avoir mené des persécutions à l'encontre des chrétiens et surtout des juifs, les relations semblent bonnes entre les dhimmî et les différentes dynasties musulmanes qui se succèdent. Si la première dynastie, celle des Aghlabides, leur marque à l'occasion une certaine

8. Kitâb al-Istibșâr, éd. S.Z. 'Abd al-Hamîd, Alexandrie, Imprimerie de l'Université, 1958, p. 155 et p. 156.

9. Al-Tidjânî, Riḥla, éd. H.H. 'Abd al-Wahhâb, Tunis, Imprimerie officielle, 1958, p. 160.

10. Joseph Cuoq, L'Église d'Afrique du Nord du II $^{e}$ au XII ${ }^{e}$ siècle, Paris, Le Centurion, 1984, p. 117, évoque « un christianisme plus ou moins répandu, plus ou moins authentiquement professé, imprégné de survivances des cultes animistes et naturistes de l'antique Berbérie ». 
animosité $^{11}$, les Fatimides et les Zirides se montrent particulièrement tolérants à l'égard des minorités ${ }^{12}$. La situation des chrétiens du Sud tunisien est différente de celle de la plupart de leurs coreligionnaires directement soumis au pouvoir arabe : la région tout entière adopte massivement la doctrine khâridjite et reconnaît l'autorité de l'imam rustumide de Tâhart qui y nomme des gouverneurs au début du IX ${ }^{\mathrm{e}}$ siècle. Les chrétiens vivent donc la vie mouvementée des khâridjites, fréquemment révoltés contre le pouvoir central ou attaqués par son armée. Le Sud tunisien est d'autant plus troublé que de fréquentes altercations opposent les ibadites majoritaires, modérés et fidèles aux imams de Tâhart, à leurs rivaux nukkârites, hostiles à cette dynastie, qui deviendront célèbres en soutenant la révolte de leur chef Abû Yazîd.

Les khâridjites ont généralement entretenu de bonnes relations avec les chrétiens et les juifs ${ }^{13}$. La place prédominante qu'occupent de nombreux chrétiens à Tâhart sous les premiers imams rustumides est bien connue : Ibn al-Ṣaghîr mentionne de nombreux notables chrétiens ('Adjam) qui font partie de l'entourage de l'imam. Sous le règne d'Aflah (m. 871), ces chrétiens, groupés sous l'autorité d'Ibn Warda, s'enrichissent grâce au commerce et construisent des demeures fortifiées et un marché. Sous le règne de son fils Abû l-Yaqzân

11. Al-Mâlikî, op. cit., I, p. 270, rapporte que selon le cadi Abû Muhriz, l'émir Ziyâdat Allâh se montrait injuste vis-à-vis des juifs et des chrétiens. Il ajoute, I, p. 476-477, qu'à la fin du IX siècle, le cadi de Kairouan, 'Abd Allâh ibn Aḥmad ibn Ṭâlib, impose aux juifs et aux chrétiens de porter sur leurs épaules des morceaux de tissu blanc, sur lesquels figurent un singe et un cochon. On cloue également sur les portes de leurs maisons des panneaux représentant des singes. Ces règles ont manifestement été très peu appliquées, même à Kairouan, et il n'existe aucune trace de leur exécution dans le Sud tunisien.

12. Voir entre autres Mohammed-Tahar Mansouri, «Juifs et Chrétiens dans le Maghreb fatimide (909-969) », in M. Barrucand (dir.), L'Égypte fatimide, son art et son histoire. Actes du colloque de Paris (mai 1998), Presses de l'Université de Paris-Sorbonne, 1999, p. 605-608 ; Hady Roger Idris, « Fêtes chrétiennes célébrées en Ifrîqiya à l'époque zîrîde », Revue Africaine, XCVIII (1954), p. 270-275.

13. Il apparaît qu'en Irak au VII ${ }^{\mathrm{e}}$ siècle, des liens privilégiés existent déjà entre les chrétiens et la communauté ibadite. Elizabeth Savage, A Gateway to Hell, a Gateway to Paradise, the North African Response to the Arab Conquest, Princeton, The Darwin Press, 1997, p. 91-97. 
(m. 894), des guerres poussent les chrétiens à faire cause commune avec l'imam et ses principaux soutiens, les Nafûsa. Plus tard, lorsque l'imam Abû Hâtim connaît des problèmes, il est de la même façon soutenu par les notables chrétiens, l'un d'eux étant connu comme défenseur de la ville ${ }^{14}$. Ibn al-Ṣaghîr parle des «chrétiens de Madjdjâna ${ }^{15}$ : il semble que cette communauté originaire de la ville de Madjdjâna s'est tant développée dans la capitale rustumide que tous les chrétiens ont été regroupés sous cette appellation. À la chute de Tâhart, certains chrétiens accompagnent l'imam à Ouargla, où leur communauté est importante au $\mathrm{x}^{\mathrm{e}}$ siècle ${ }^{16}$.

Les historiens ibadites, contrairement à Ibn al-Șaghîr, parlent très peu des chrétiens. Abû Zakariyyâ' rapporte uniquement les propos d'un savant qui compare avec admiration un membre de la tribu des Nafûsa et ses compagnons à Jésus et ses apôtres ${ }^{17}$. Al-Shammâkhî note qu'un grand savant ibadite du $\mathrm{IX}^{\mathrm{e}}$ siècle avait un esclave chrétien ; un autre avait une mère chrétienne et, lorsqu'il était encore nourrisson, il ne tétait pas sa mère quand elle avait bu du vin ${ }^{18}$ ! Il évoque également la conversion d'une chrétienne à l'islam, après son mariage avec un ibadite ${ }^{19}$. Il semble que certains groupes ibadites ont intégré les chrétiens et les juifs dans leur communauté, si ces derniers acceptaient de prononcer la profession de foi musulmane en ajoutant après l'évocation de Muḥammad, l'envoyé de Dieu, les mots « (envoyé) aux Arabes, mais pas à nous » 20 .

14. Ibn al-Saghîr, Akhbâr al-a'imma l-rustumiyyîn, éd. M. Talbi in Cahiers de Tunisie, XXIII (1975), p. 336, p. 346 et p. 359. Par ailleurs, Ibn al-Ṣaghîr note, p. 354, que les Nafûsa considèrent l'imam Abû 1-Yaqzân de la même façon que les chrétiens considèrent Jésus.

15. Ibn al-Saghîr, op. cit., p. 336-337.

16. Tadeusz Lewicki, « Une communauté chrétienne dans l'oasis de Ouargla au $\mathrm{x}^{\mathrm{e}}$ siècle », in Études maghrébines et soudanaises (I), Varsovie, Éditions Scientifiques de Pologne, 1976, p. 85-88.

17. Abû Zakariyyâ', Kitâb al-Sîra wa-akhbâr al-a'imma, éd. 'A. Ayyûb, Tunis, Al-dâr al-tûnisiyya li-1-nashr, 1985, p. 259.

18. Al-Shammâkhî, Kitâb al-Siyar, éd. partielle M. Hasan, Tunis, Kulliyat al-'ulûm al-insâniyya wa-l-idjtimâ‘iyya, 1995, p. 154 et p. 175.

19. Al-Shammâkhî, op. cit., p. 190.

20. Charles-Emmanuel Dufourcq, «La coexistence des chrétiens et des musulmans dans al-Andalus et dans le Maghrib au $\mathrm{X}^{\mathrm{e}}$ siècle », in Occident et Orient au $x^{e}$ siècle, Publications de l'Université de Dijon, 1979, p. 216 ; Pessah 
Les ibadites n'ont pas hésité à convertir les anciennes églises à leur propre culte. Les sources énumérant les endroits vénérés du djebel Nafûsa mentionnent plusieurs mosquées qui sont dites apostoliques ou qui ont conservé leur nom d'église/kanîsa ${ }^{21}$. Si cette tendance paraît propre au djebel, le Kitâb al-Istibṣâr évoque également à Gafsa une «masdjid al-Ḥawâriyyîn » ${ }^{22}$. Cette «mosquée des apôtres » dont le nom a souvent été mal compris ${ }^{23}$ est certainement, de la même façon, une ancienne église reconvertie en mosquée. Georges Marçais a noté à Sadrâta que l'art khâridjite des $\mathrm{x}^{\mathrm{e}}$ et $\mathrm{XI}^{\mathrm{e}}$ siècles s'inspire directement de l'art chrétien de l'Afrique préislamique; le décor ressemble à celui des basiliques rurales maghrébines et il apparaît que les Berbères ibadites ont longtemps gardé des influences chrétiennes ${ }^{24}$. Le christianisme berbère aurait également pu influencer le khâridjisme par la large place accordée aux œuvres par rapport à la foi, ainsi que par les notions de pureté

Shinar, «Réflexions sur la symbiose judéo-ibadite en Afrique du Nord », in M. Abitbol (éd.), Communautés juives des marges sahariennes du Maghreb, Jérusalem, Yad Izhak Ben-Zvi, 1982, p. 85. Il faut toutefois noter que le savant ibadite al-Djîtâlî (m. 1350), qui a vécu dans le djebel Nafûsa et à Djerba, préconise de ne pas saluer les dhimmî, de ne pas leur serrer la main et d'éviter de partager leurs repas. Pierre Cuperly, Introduction à l'étude de l'ibadisme et de sa théologie, Alger, Office des Publications Universitaires, 1984, p. 144.

21. La liste ancienne Tasmiya mashâhid al-djabal, reproduite dans René Basset, «Les sanctuaires du Djebel Nefousa », réimpr. in Cahiers de Tunisie, XXIX (1981), p. 372-373, mentionne huit kanîsa. La description du djebel Nafûsa, rédigée en berbère à la fin du XIX ${ }^{\mathrm{e}}$ siècle par Brâhîm ibn Slîmân alShammâkhî, signale quatre mosquées dites apostoliques. Adolphe de Calassanti Motylinski, Le Djebel Nefousa, Paris, Ernest Leroux, 1898, p. 74, p. 75, p. 86 et p. 93. J.W. Allan, "Some Mosques of the Jebel Nafusa », Libya Antiqua, IX-X (1972-1973), p. 168-169, note que vers 1970 existaient toujours trois mosquées « apostoliques », une kanîsa et trois mosquées nommées taghlîs, un nom dérivé d'ecclesia.

22. Kitâb al-Istibṣâr (op. cit.), p. 152.

23. Paul-Louis Cambuzat, L'évolution des cités du Tell en Ifrîkiya du VII au XI siècle (II), Alger, Office des Publications Universitaires, 1986, p. 119, et H.R. Idris, La Berbérie orientale sous les Zîrîdes, Paris, Adrien-Maisonneuve, 1962, p. 471, parlent de mosquée des « Hawwâra ».

24. Georges Marçais, «Art chrétien d'Afrique et art berbère », Annali dell'Istituto Universitario Orientale di Napoli, III (1949), p. 70-71. 
morale et de repentir ${ }^{25}$. Un lien encore plus fort peut être établi avec le schisme chrétien donatiste dont on a conservé des témoignages jusqu'en 722 , soit peu avant les premières révoltes khâridjites ${ }^{26}$. De nombreuses populations anciennement donatistes, comme celles du Djérid et du Nafzâwa ${ }^{27}$, ont rejoint le combat des khâridjites. Les deux doctrines défendent en effet des valeurs communes : l'égalité sociale, une rigoureuse discipline religieuse, l'importance de la qualité de celui qui dirige la communauté et le droit de le démettre s'il est indigne, le rejet de la religion officielle et du pouvoir exercé par les maîtres du pays, venus de l'étranger ${ }^{28}$.

En dépit des relations cordiales qui ont sans doute majoritairement existé entre les chrétiens et les ibadites des oasis, on ne peut manquer de signaler qu'Ibn 'Abd al-Ḥakam et Ibn Hawqal évoquent chacun une révolte khâridjite contre les dhimmî. La première anecdote se rapporte aux premiers temps de la propagation du khâridjisme dans le Sud tunisien, sous sa forme extrémiste sufrite, qui disparaîtra rapidement. Ibn 'Abd al-Ḥakam relate que vers 742, des Berbères ṣufrites se sont insurgés dans le Nafzâwa et ont mis en captivité les dhimmî de la région. Les troupes tripolitaines ont gagné le Nafzâwa et leur ont livré bataille. Les șufrites ont été massacrés et tous les prisonniers ont été libérés ${ }^{29}$. Cette attaque contre les dhimmî est bien étonnante et on peut l'attribuer peut-être à la ferveur acharnée des nouveaux convertis. Il est possible également que les ṣufrites aient

25. Ch.-E. Dufourcq, op. cit., p. 218 ; Émile Masqueray, «Les kânoûn des Beni-Mzab », Études et documents berbères, 13 (1995), p. 212 et sqq.

26. E. Savage, op. cit., p. 98.

27. En 411, il y a des évêchés catholiques et donatistes à Gafsa, Gabès, Thiges, Tozeur et à Turris au Nafzâwa, ainsi qu'un évêché donatiste à Nefta. J. Mesnage, «Le christianisme en Afrique », p. 512 et p. 516-518.

28. Sur le rapprochement entre donatisme et khâridjisme, É. Masqueray, Chronique d'Abou Zakaria, Alger, V. Aillaut, 1878, p. LXIII-LXV et p. LXXI ; G. Fiaccadori, « Kharidjites et donatistes », Annales E.S.C., 38 (1983), p. 473474 ; J. Mesnage, «Le christianisme en Afrique », p. 500 ; G. Marçais, « Art chrétien d'Afrique », p. 71 ; E. Savage, op. cit., p. 97-98.

29. Ibn 'Abd al-Hakam, Futûh Miṣr, éd. C. Torrey, New Haven, Yale University Press, 1922, p. 223. 
cherché à punir les dhimmî d'une éventuelle collaboration avec les Arabes $^{30}$.

Plus tard, Ibn Hawqal rapporte que les Berbères hérétiques et dangereux peuplant les alentours de Gabès ${ }^{31}$ se sont approprié les biens des commerçants et des dhimmî, après avoir assiégé Gabès et incendié son faubourg. Après cette attaque, leurs méfaits ont cessé car le chef des Șanhâdja a exterminé tous ceux qui y avaient participé $^{32}$. Cette insurrection khâridjite, manifestement narrée par le seul Ibn Ḥawqal, daterait du tout début du règne ziride, juste après le départ d'al-Mu'izz pour Le Caire ${ }^{33}$. Cette fois, elle ne semble pas dirigée intentionnellement contre les dhimmî mais s'apparenter davantage à une razzia ayant pour seul but d'enrichir les rebelles.

\section{TÉMOIGNAGES SUR LES CHRÉTIENS AVANT LA CONQUÊTE ALMOHADE}

Les nombreuses communautés chrétiennes du Sud tunisien sont mentionnées par les premiers géographes musulmans. À la fin du $\mathrm{IX}^{\mathrm{e}}$ siècle, selon al-Ya'qûbî, on trouve dans les cités de la Qasṭ̂liya des Afâriqa, des Berbères et des non-Arabes ('Adjam) descendants des anciens Rûm. À Bishshara, ville principale du Nafzâwa, les habitants sont des Berbères et des descendants des anciens Afâriqa ${ }^{34}$. Al-Ya'qûbî distingue clairement les Afâriqa des Rûm. Les Rûm sont les Byzantins qui ont manqué l'exode provoqué par l'arrivée des Arabes et sont restés de pure race ; ils disparaîtront rapidement et ne seront déjà plus mentionnés par al-Bakrî. Les Afâriqa, descendants

30. André Chouraqui, Histoire des Juifs en Afrique du Nord, Paris, Hachette, 1985, p. 111.

31. Il s'agit certainement des Mazâta ibadites de Gabès. T. Lewicki, Les ibadites en Tunisie au Moyen Âge, Rome, Academia Polacca di Scienze e Lettere, Conferenze fasc. 6, 1958, p. 8, n. 21. Les « Mazâtat Qâbis » sont cités dans les sources ibadites : Abû Zakariyyâ', op. cit., p. 213-214 ; al-Shammâkhî, op. cit., p. 319 et p. 391.

32. Ibn Hawqal, Kitâb Șûrat al-arḍ, éd. M.J. De Goeje et J.H. Kramers, Leyde, Brill, 1967 (B.G.A., II), p. 70.

33. H.R. Idris, La Berbérie orientale, p. 46-47.

34. Al-Ya'qûbî, Kitâb al-Buldân, éd. M.J. De Goeje, Leyde, Brill, 1967, (B.G.A., VII), p. 350. 
des Berbères romanisés, forment la population christianisée la plus ancienne de l'Ifrîqiya ; ils sont le plus souvent sédentaires, citadins ou ruraux. Si les Rûm perpétuent l'usage du grec, les Afâriqa parlent un latin typiquement africain, lié au culte chrétien. Dans le Djérid, région éloignée des centres d'arabisation, les Afâriqa ont pu conserver leur langue et leur foi, ou tout au moins le souvenir de leur récente conversion ${ }^{35}$.

On ignore quel encadrement clérical subsiste dans les oasis après la conquête arabe. En 883, la «Liste de Léon Le Sage » laisse penser que Gafsa et Qastîliya sont encore des évêchés, mais cette source doit être considérée avec la plus grande prudence ${ }^{36}$. Il y a sans doute, au $\mathrm{x}^{\mathrm{e}}$ siècle tout au moins, une communauté chrétienne organisée et des liens étroits entre les chrétiens de Gafsa, de la Qasțiliya et du Nafzâwa. Ils sont sans doute également en contact avec ceux de la Tripolitaine dont l'existence est attestée jusqu' aux $\mathrm{x}^{\mathrm{e}}$-XI $\mathrm{x}^{\mathrm{e}}$ siècles, et avec ceux «de Madjdjâna » installés à Ouargla avec lesquels ils entretiennent certainement de fréquentes relations commerciales ${ }^{37}$. La révolte du chef nukkârite Abû Yazîd (m. 947) représente sans aucun doute une période pénible pour les chrétiens, et particulièrement la couvaison de cette révolte pendant laquelle il s'en prend aux populations du Djérid. Si Tadeusz Lewicki impute à Abû Yazîd, qui aurait contraint les paisibles sédentaires à fuir leurs villages, «la ruine de l'élément chrétien et roman du Maghreb ${ }^{38}$, aucun texte

35. G. Marçais, «La Berbérie au IX ${ }^{\mathrm{e}}$ siècle d'après al-Ya 'qûbî », Revue Africaine, LXXXV (1941), p. 45-49.

36. Qastîliya (qui désigne ici Tozeur, chef-lieu de la Qastîliya, et non la région tout entière) est reprise sous la forme Castellai dans tous les manuscrits, Gafsa est notée Capsès dans le manuscrit d'Oxford et Campsês dans les autres manuscrits. Yûsuf Kâmal, Monumenta cartographica Africae et Aegypti, Le Caire-Leyde, 1926-1951, III, fasc. 1, p. 535-536. Selon Christian Courtois, « Grégoire VII et l'Afrique du Nord, remarques sur les communautés chrétiennes d'Afrique au XI ${ }^{\mathrm{e}}$ siècle », Revue Historique, CXCV (1945), p. 108, n. 2, cette liste est manifestement une démarcation de listes plus anciennes.

37. G. Marçais, «La Berbérie au IX ${ }^{\mathrm{e}}$ siècle », p. 49 ; T. Lewicki, «Une communauté chrétienne », p. 89-90.

38. T. Lewicki, «Une langue romane oubliée de l'Afrique du Nord. Observations d'un arabisant », Rocznik Orientalistyczny, XVII (1953), p. 421. 
ne sous-entend que les chrétiens auraient plus souffert que les musulmans des méfaits commis par le chef nukkârite. Toutefois, pendant cette révolte, l'empereur byzantin dépêche une ambassade auprès du calife fatimide pour s'enquérir des événements qui frappent l'Ifrîqiya, cette inquiétude montrant qu'il y avait sans doute une communauté chrétienne qui dépendait de Byzance ${ }^{39}$.

Al-Qâbisî (m. 1012) indique dans une fatwâ que certaines églises de la Qasṭ̂liya sont déjà en ruine. Abû Zakariyyâ' al-Shaqrâtịî̂ (m. 1037) l'interroge à ce sujet : les musulmans ont utilisé les pierres des églises chrétiennes en ruine pour bâtir une citerne-réservoir destinée à leurs coreligionnaires, surmontée d'une mosquée. Le savant de Tozeur veut savoir s'il est licite d'utiliser cette eau pour les ablutions. Al-Qâbisî lui répond que si ces églises sont déjà en ruine à l'arrivée des musulmans et que les chrétiens ne les ont pas utilisées depuis lors, on peut sans souci utiliser l'eau de la citerne et prier dans la mosquée. Si, par contre, les chrétiens ont continué à employer les églises après la conquête musulmane et que celles-ci sont tombées en ruine plus tard, ces pierres restent leur propriété tant que leur statut de dhimmî demeure en vigueur. Ils peuvent ainsi réclamer des pierres intactes qui auraient été prises entre-temps par les musulmans, afin de réparer leurs lieux de culte. Si ces pierres ont été endommagées par les musulmans au cours de leur réemploi, les chrétiens ont le droit de recevoir un dédommagement et d'affecter cette somme à la réparation de leurs biens ${ }^{40}$. Ce texte prouve de façon certaine qu'une communauté chrétienne vit encore dans la Qasṭ̂liya au début du $\mathrm{XI}^{\mathrm{e}}$ siècle et montre le respect qu'accordent certains juristes musulmans au statut de dhimmî. Plus tard, une fatwâ d'al-Lakhmî (m. 1085) déclare licite la vente des habous chrétiens au profit des habous musulmans ; un cadi en profite pour

39. M. Mansouri, op. cit., p. 606.

40. Si al-Qâbisî se montre tolérant à l'égard des chrétiens, un autre juriste déconseille fortement d'utiliser l'eau de la citerne pour les ablutions. H.R. Idris, « La vie intellectuelle en Ifrîqiya méridionale sous les Zîrîdes d'après Ibn alShabbât », in Mélanges d'histoire et d'archéologie de l'Occident musulman. Hommage à Georges Marçais, Alger, 1957, II, p. 105-106. 
vendre des habous chrétiens de Tozeur destinés à l'entretien des églises en ruine et en offrir le montant aux musulmans nécessiteux ${ }^{41}$.

Au milieu du $\mathrm{XI}^{\mathrm{e}}$ siècle, l'arrivée des Arabes Banû Hilâl entraîne peut-être des modifications dans la vie des chrétiens. Joseph Cuoq estime qu'ils fuient en nombre les campagnes pour les grosses villes, les ports tels Mahdiyya ou Bougie, ou les oasis du sud ${ }^{42}$. Aucun document ne confirme cependant qu'il y ait eu alors une augmentation du nombre de chrétiens dans le Djérid. Dans deux lettres datées de 1053, le pape Léon IX déplore, en pleine crise arabe, l'affaiblissement considérable de l'Église d'Afrique ; il n'y subsiste que cinq évêques et les deux principaux, celui de Carthage et celui de Mahdiyya/ Gummi, se disputent l'archevêché. Les trois autres diocèses évoqués par le pape sont sujets à discussion; il pourrait peut-être s'agir de Gabès ou de Gafsa ${ }^{43}$. En 1076, le pape Grégoire VII regrette que l'on ne trouve plus en Afrique les trois évêques nécessaires à l'ordination d'un nouvel évêque : il ne reste plus que celui de Carthage et celui de Bougie, récemment nommé à la demande du souverain ḥammâdide al-Nâșir pour sa nouvelle capitale ${ }^{44}$. Il est donc probable que l'évêché de Mahdiyya a disparu et, à plus forte raison, celui de Gafsa. Dans le milieu du XII ${ }^{\mathrm{e}}$ siècle cependant, une communauté chrétienne subsiste assurément dans cette ville, puisqu'al-Idrîsî constate en 1154 que la plupart des habitants de Gafsa s'expriment en langue latine d'Afrique/ bi-l-lisân al-latînî al-ifrîq $\hat{l}^{45}$. Ce passage relatif à la population de

41. Ibid., p. 105. Jusqu'à la fin de l'époque ziride, des habous chrétiens de Tozeur sont affectés à l'entretien des églises. H.R. Idris, La Berbérie orientale, p. 608.

42. J. Cuoq, op. cit., p. 169.

43. Ces deux lettres en latin sont reproduites dans les documents de M.L. de Mas-Latrie, Traités de paix et de commerce et documents divers concernant les relations des chrétiens avec les Arabes de l'Afrique septentrionale au Moyen Âge, Paris, Henri Plon, 1866-1872, p. 1-5. M. Talbi, op. cit., p. 325 propose Gafsa. X. de Planhol, op. cit., p. 199, indique que Gabès est un des cinq évêchés de 1053.

44. Ces lettres en latin sont reproduites dans les documents de Mas-Latrie, op. cit., p. 6-8. X. de Planhol, op. cit., p. 200, met ce nouvel affaiblissement des chrétiens en rapport avec « l'invasion » des Banû Hilâl.

45. Al-Idrîsî, Kitâb Nuzhat al-mushtâq/Opus geographicum, éd. E. Cerulli et al., Rome-Naples, 1972, fasc. 3, p. 278. L'Encyclopédie de l'Islam dit à l'article Gafsa que jusqu'au XII ${ }^{\mathrm{e}}$ siècle, la foi chrétienne était encore professée « par une large partie de la population », ce qui paraît pour le moins exagéré. 
langue latine ne peut être mis en doute. Al-Idrîsî est savant et connaît le latin ; le parler qui subsiste à Gafsa n'en est pas moins éloigné que les dialectes romans de l'Italie ou de l'Espagne, et le géographe peut facilement le qualifier de «langue latino-africaine », selon l'expression de Tadeusz Lewicki. Ce dernier souligne que latînî possède une double signification en arabe médiéval, désignant d'une part la langue latine et d'autre part les dialectes romans; grâce à sa familiarité avec le français et le dialecte roman sicilien, al-Idrîsî peut affirmer que la langue entendue à Gafsa est bien un dialecte roman, mais qui est caractérisé par des formules différentes de ce qu'il a connu en Sicile, ce qui l'amène à le définir comme africain ${ }^{46}$. À la même époque, un autre centre important de la survivance du christianisme est sans doute Gabès, qu'al-Idrîsî nomme « la ville des Afâriqa $»^{47}$. La ville est placée sous protectorat normand pendant une dizaine d'années (c. 1148-1158), mais conserve ses dirigeants locaux. Certains chrétiens choisissent peut-être de s'y installer à cette époque, le plus grand nombre gagnant Mahdiyya où le roi normand Guillaume $\mathrm{I}^{\mathrm{er}}$ nomme en 1157 un archevêque relevant de Palerme ${ }^{48}$.

46. T. Lewicki, «Une langue romane oubliée», p. 417 et p. 430-431; Serge Lancel, «La fin et la survie de la langue latine en Afrique du Nord, état des questions », Revue des études latines, LIX (1981), p. 290. Dans la seconde moitié du $\mathrm{xv}^{\mathrm{e}}$ siècle, l'humaniste romain Paolo Pompilio signale, en un témoignage manifestement digne de foi, que sur le territoire de Gafsa existe une contrée peuplée de nombreux villages où les villageois parlent dans une latinité presque intacte, de même que dans l'Aurès. Jean-Louis Charlet, «Un témoignage humaniste sur la latinité africaine et le grec parlé par les "Choriates" : Paolo Pompilio », Antiquités Africaines, XXIX (1993), p. 243-245. Il ne s'agit sans doute plus du latin africain observé par al-Idrîsî, mais d'un latin parlé par des représentants de «l'église immigrée ».

47. Al-Idrîsî, op. cit., p. 297. Ibn Khurradâdhbih, Kitâb al-Masâlik wa-lmamâlik, éd. trad. M.J. De Goeje, Leyde, Brill, 1967 (B.G.A., VI), p. 86, signale déjà Gabès comme la ville des Afâriqa non-arabes. Al-Bakrî, Kitâb al-Mughrib fî dhikr bilâd Ifrîqiya wa-l-Maghrib, éd. trad. W. Mac Guckin de Slane, Paris, Adrien-Maisonneuve, 1965, p. 17/41, confirme que sa population se compose en partie d'Afâriqa.

48. H.R. Idris, La Berbérie orientale, p. 761. 
Les auteurs modernes ont généralement attribué aux Almohades et à leur fanatisme religieux la disparition du christianisme maghrébin ${ }^{49}$, en se basant sur le fait que plusieurs textes arabes rapportent que 'Abd al-Mu'min laissa aux chrétiens et aux juifs de Tunis le choix entre la conversion et la mort ${ }^{50}$. L'interprétation de cette phrase a fait couler beaucoup d'encre, certains historiens estimant que les chrétiens refusant l'islam furent réellement exécutés, d'autres arguant du fait qu'il n'existe aucune preuve d'un massacre de chrétiens ${ }^{51}$. En ce qui concerne le Sud tunisien, les nombreux documents relatifs à la conquête almohade que nous avons étudiés, y compris les lettres officielles décrivant ces événements, ne font pas une seule fois état d'atteintes portées à l'encontre des chrétiens ${ }^{52}$.

Même si l'on exclut toute idée de violences manifestées contre les dernières communautés chrétiennes autochtones, il est un fait que la situation de ces dernières évolue dès la conquête almohade. Désormais, les chrétiens d'Ifrîqiya forment en grande partie, selon l'expression de Christian Courtois, « une église immigrée » : arrivés récemment du monde chrétien, ce sont des marchands, des religieux, des esclaves, des soldats au service des musulmans ou encore des captifs. Les nations chrétiennes comptent alors de nombreux

49. Parmi ceux qui attribuent la fin du christianisme aux Almohades, voir entre autres H.R. Idris, La Berbérie orientale, p. 761 ; Ch. Courtois, op. cit., p. 121 ; Robert Brunschvig, La Berbérie orientale sous les Hafșides des origines à la fin du XV siècle, Paris, Adrien-Maisonneuve, 1982, I, p. 5 ; J. Cuoq, op. cit., p. 179. Ils se fondent également sur al-Marrâkushî, Kitâb alMu'djib fî talkhîs akhbâr al-Maghrib, éd. R. Dozy, Amsterdam, Oriental Press, 1968, p. 223, qui écrit qu'à son époque, sous le règne de Ya'qûb (11841198), juifs et chrétiens ne bénéficient plus du statut de dhimmî et qu'il n'y a plus dans le Maghreb ni synagogue ni église.

50. Ibn al-Athîr, op. cit., XI, p. 242 ; al-Tidjânî, op. cit., p. 347. L'interprétation de cette phrase a fait couler beaucoup d'encre. Jean-Pierre Molénat, «Sur le rôle des Almohades dans la fin du christianisme local au Maghreb et en al-Andalus », Al-Qanțara, XVIII (1997), p. 400-401, fournit d'autres sources orientales.

51. Voir notamment J.-P. Molénat, op. cit., p. 399-400 ; M. Talbi, op. cit., p. 328-329.

52. V. Prevost, L'aventure ibadite dans le Sud tunisien. Effervescence d'une région méconnue, Thèse non publiée de l'Université Libre de Bruxelles, 2002, p. 264-270. 
comptoirs maghrébins, possédant la plupart du temps un lieu de culte; il en va ainsi pour Gabès ${ }^{53}$. Ainsi, l'avenir des chrétiens autochtones de cette ville se trouve résolu puisqu'ils bénéficient d'un nouvel encadrement qui assure leur survie. À Gafsa, fortement isolée de la côte, la situation des chrétiens est tout autre. Lors de sa conquête par les Almohades en 1159, la ville subit un rude siège, sur lequel subsistent d'abondants documents. La communauté chrétienne à laquelle fait allusion al-Idrîsî quelques années plus tôt en souffre certainement mais rien ne prouve qu'elle soit plus inquiétée que les autres habitants de la ville. À notre connaissance, il n'existe plus par la suite de mention convaincante de la survie des chrétiens gafsiens ${ }^{54}$. Le Djérid et le Nafzâwa semblent être désormais les deux seules régions où demeurent des communautés chrétiennes autochtones. Joseph Cuoq suppose qu'elles accueillent alors de nouveaux fidèles, réfugiés dans le Sud tunisien pour fuir les Almohades ${ }^{55}$.

\section{TÉMOIGNAGES SUR LES CHRÉTIENS APRÈS LA CONQUÊTE ALMOHADE}

Trois arguments principaux prouveraient la permanence d'un christianisme local dans les oasis après la conquête almohade. Ils se fondent sur le Kitâb al-Istibṣâr, sur Ibn Khaldûn et sur Mawlâ Aḥmad :

1) À la fin du XII ${ }^{\mathrm{e}}$ siècle, des chrétiens vivraient encore à $\mathrm{Nefta}^{56}$. Cette affirmation est tirée du Kitâb al-Istibṣâr, qui signale que les

53. Ch. Courtois, op. cit., p. 107 ; Henri Teissier, Histoire des chrétiens d'Afrique du Nord, Paris, Desclée, 1991, p. 68.

54. Selon François Arnoulet, «L'Église mozarabe en Tunisie au xIII siècle », in Actes $d u v^{e}$ colloque international sur l'histoire et l'archéologie de l'Afrique $d u$ Nord, Avignon, 1990, p. 250, les franciscains et les dominicains venus en Ifrîqiya auraient été en relation vers 1220 avec des non-musulmans de la région de Gafsa, des Blancs parlant le berbère ; ces gens auraient possédé une cloche et des livres du temps de Byzance, n'auraient pris qu'une femme en mariage et auraient mélangé leur vin à du bouillon pour s'accommoder au Coran. Cette information doit être considérée avec prudence car ce bref article, critiqué à juste titre par J.-P. Molénat, op. cit., p. 406, n. 64, compte plusieurs erreurs.

55. J. Cuoq, op. cit., p. 172.

56. Ibid., p. 144, repris par T. Lewicki, «Une communauté chrétienne », p. 89 et M. Talbi, op. cit., p. 338. 
habitants de Nefta sont les descendants des Rûm ${ }^{57}$. Ceci ne prouve en aucun cas qu'ils sont chrétiens : il peut s'agir d'une population que l'on distingue encore par son aspect physique, un costume particulier par exemple, ou certaines de ses coutumes, même si elle est convertie à l'islam depuis plusieurs siècles. De même, le fait que le Kitâb al-Istibṣâr indique que la famille des Banû Bahlûl, les maîtres d'al-Ḥâmma, descend des Rûm, pourrait laisser croire à une survivance du christianisme, alors qu'il paraît évident que les Banû Bahlûl sont musulmans : l'auteur dit d'ailleurs clairement que les Rûm dont ils descendent se sont convertis à l'islam pour conserver leurs biens ${ }^{58}$. L'auteur du Kitâb al-Istibṣâr considère de toute façon, comme cela a été noté plus haut, que les habitants du Djérid ont adopté l'islam. Il faut noter de plus que les passages évoqués ici sont bien antérieurs à la conquête almohade, puisqu'il a été démontré que les ajouts qu'apporte le Kitâb al-Istibṣâr au texte d'al-Bakrî sont le résultat des observations faites par son auteur en Ifrîqiya aux environs de $1135^{59}$. Même si des chrétiens autochtones vivent encore au XII ${ }^{\mathrm{e}}$ siècle dans les oasis, cet argument ne peut être pris en compte pour prouver leur existence sous les Almohades, puisqu'il est mal daté et qu'il mentionne de simples descendants des Rûm.

2) $\mathrm{Au} \mathrm{XIV}{ }^{\mathrm{e}}$ siècle, des communautés chrétiennes subsisteraient toujours dans le Nafzâwa. Cette affirmation, reprise par de nombreux chercheurs ${ }^{60}$, se base sur le témoignage d'Ibn Khaldûn. L'historien évoque des $m u$ 'âhidûn/confédérés d'origine franque qui, à l'époque

57. Kitâb al-Istibṣâr (op. cit.), p. 156. Le même ouvrage signale, p. 155, que les habitants de Tozeur sont également les descendants des Rûm. Lorsqu'il évoque Tinnîs et Damiette, p. 88, il dit clairement que des chrétiens/naṣârâ y vivent sous le statut de la dhimma.

58. Ibid., p. 157.

59. Nehemia Levtzion, «The Twelfth-Century Anonymous Kitâb alIstibșâr : a History of a Text », in Islam in West Africa, Aldershot-Brookfield, Variorum Reprints, 1994, p. 201-217.

60. Ch. Courtois, op. cit., p. 110-111 ; R. Brunschvig, op. cit., I, p. 430 ; X. de Planhol, op. cit., p. 201 ; T. Lewicki, «Une communauté chrétienne », p. 89 ; M. Talbi, op. cit., p. 344 ; J. Cuoq, op. cit., p. 172 ; I. Hrbek et M. El Fasi dans Histoire générale de l'Afrique (III), Paris, Présence Africaine/Edicef/ UNESCO, 1997, p. 73. L'Encyclopédie de l'Islam relaie cette information à l'article Nafzâwa, mais également à l'article Nefta. 
de la conquête musulmane, se sont établis dans le Nafzâwa sous le statut de dhimmî et ont payé la djizya; leurs descendants y vivent toujours à son époque. Ailleurs, Ibn Khaldûn précise que leurs ancêtres sont venus de Sardaigne ${ }^{61}$. On sait que les relations entre la Sardaigne et l'Ifrîqiya étaient fréquentes : la Sardaigne avait fait partie de l'État vandale et était rattachée au diocèse d'Afrique pendant la période byzantine $^{62}$. Toutefois, comme le souligne Georges Marçais, par ailleurs partisan de l'extrême longévité de ces chrétiens, il paraît curieux que des Sardes aient quitté leur île pour s'installer sur une terre qui venait d'être conquise par les musulmans; il estime qu'Ibn Khaldûn a voulu ainsi expliquer leur présence ${ }^{63}$. S'il est indéniable que des chrétiens ont longtemps payé la djizya dans cette région, les termes employés par Ibn Khaldûn n'impliquent pas que cette situation a perduré à son époque. Nous prenons donc cette information avec la plus grande prudence ${ }^{64}$.

3) À Tozeur, des chrétiens demeureraient jusqu'au XVIII ${ }^{\mathrm{e}}$ siècle. Cette affirmation, à nouveau relayée par de nombreuses études ${ }^{65}$, est basée, à notre connaissance, sur le seul témoignage du voyageur Mawlâ Aḥmad, qui traverse le Djérid en 1709. Le voyageur, traduit par Adrien Berbrugger, dit que « les gens de Touzeur sont un reste des

61. Ibn Khaldûn, Kitâb al- 'ibar, Beyrouth, Dâr al-kutub al- 'ilmiyya, 1992, VI, p. 137 et p. 529; Histoire des Berbères et des dynasties musulmanes de l'Afrique septentrionale, trad. W. Mac Guckin de Slane, Paris, Paul Geuthner, 1999, I, p. 231 et III, p. 156. À noter que Paolo Pompilio, évoquant la latinité presque intacte des habitants du territoire de Gafsa, affirme que quand il y a brisure des mots latins, ils passent aux sonorités et aux pratiques du sarde. Pour lui, ce territoire a pour nom arabe Niczensa. Ce terme a été lu Nemencha, peut-être s'agit-il du Nafzâwa ? J.-L. Charlet, op. cit., p. 243 et p. 244, n. 1.

62. Ch. Courtois, op. cit., p. 115, n. 2.

63. G. Marçais, « La Berbérie au IXe siècle », p. 49.

64. J.-P. Molénat, op. cit., p. 407, à la différence de la plupart des historiens contemporains, attire l'attention sur l'ambiguiité que présentent ces extraits et estime que leur traducteur, le baron de Slane, «a forcé le sens de ces deux passages » de façon à faire admettre que des chrétiens vivaient encore à cette époque dans le Nafzâwa.

65. G. Marçais, «La Berbérie au IX ${ }^{\mathrm{e}}$ siècle », p. 49, n. 32 ; I. Hrbek et M. El Fasi, op. cit., p. 73 ; Ch. Courtois, op. cit., p. 111, n. 1 ; H.R. Idris, La Berbérie orientale, p. 761 ; T. Lewicki, « Une communauté chrétienne », p. 89. 
chrétiens qui étaient autrefois en Afrik'ïa, avant que les musulmans en fissent la conquête ; la plupart des habitants du Djerid ont cette même origine, parce que, lorsque les Arabes s'emparèrent du pays, les vaincus se firent musulmans pour sauver leurs familles et leurs biens ». Plus loin, il ajoute qu'à l'arrivée des musulmans, «les Grecs s'en allèrent, sauf ceux qui se firent musulmans et ceux qui payèrent le djezïa comme les gens du Djerid ${ }^{66}$. Ce texte n'offre en aucun cas une preuve de la survivance de chrétiens dans la région au début du XviII ${ }^{\mathrm{e}}$ siècle! Les paroles de Mawlâ Aḥmad sont directement tirées du texte d'al-Tidjânî, de même que les longs passages qui précèdent et qui suivent ces extraits ; Mawlâ Aḥmad le précise d'ailleurs clairement à une occasion ${ }^{67}$. Outre cela, ces deux renseignements figurent déjà, comme on l'a vu, dans le Kitâb al-Istibșâr, et remontent donc au $\mathrm{XII}^{\mathrm{e}}$ siècle. Nous renvoyons dès lors aux observations que nous avons faites plus haut au sujet de ce passage. L'existence de chrétiens autochtones à Tozeur à une époque aussi tardive, justifiée par une interprétation négligente de Mawlâ Ahmad, doit donc être totalement remise en question si d'autres sources, cette fois réellement dignes de foi, ne viennent pas étayer cette thèse. Xavier de Planhol propose une autre interprétation du texte : il admet qu'il n'y avait plus de chrétiens à l'époque de Mawlâ Aḥmad, ce dernier faisant simplement allusion aux origines chrétiennes de la population. Mais il retient la présence d'églises en ruine observée par le voyageur, alors que cette information provient également d'al-Tidjânî ${ }^{68}$. Il estime que les coutumes décrites par Mawlâ Aḥmad «concordent à donner l'impression de mauvais Musulmans sans doute fraîchement convertis et encore marqués par l'ignominie de leurs origines » et en conclut que la disparition du

66. Mawlâ Ahmad, Voyage de Moula-Ah'med, trad. A. Berbrugger in Exploration scientifique de l'Algérie pendant les années 1840, 1841, 1842 (IX), Paris, Imprimerie royale, 1846, p. 289 et p. 290.

67. Mawlâ Aḥmad, op. cit., p. 288-292, reprenant al-Tidjânî, op. cit., p. 157-162. Ce dernier, p. 160, évoque « ceux qui se firent musulmans ou qui s'acquittèrent de la djizya».

68. Elle remonte à Ibn al-Shabbât. Voir infra, n. 70. 
christianisme ne devait pas être très ancienne, remontant sans doute au XVI ${ }^{\mathrm{e}}$ ou au XVII ${ }^{\mathrm{e}}$ siècle $^{69}$.

Les pages qui précèdent montrent que les arguments avancés habituellement pour justifier la survivance d'une communauté chrétienne autochtone dans les oasis, jusqu' au XIV ${ }^{\mathrm{e}}$ ou même jusqu'au $\mathrm{XVIII}^{\mathrm{e}}$ siècle, sont peu fiables ${ }^{70}$. Deux sources dignes de foi peuvent se révéler, par leur silence, beaucoup plus utiles. Ibn al-Shabbât de Tozeur (m. 1282), posant la question du statut juridique de Gafsa et de la Qastîliya, note qu'il y subsiste à son époque des emplacements d'églises chrétiennes en ruine ${ }^{71}$. Au début du XIV siècle, al-Tidjânî séjourne longuement dans ces oasis ; il n'évoque à aucun moment la présence de chrétiens, alors qu'il fournit tout comme Ibn al-Shabbât quantité de renseignements originaux sur la région. Il semble bien dès lors que le déclin final du christianisme dans le Djérid s'est produit pendant le XIII ${ }^{\mathrm{e}}$ siècle.

Il faut noter que la tradition des églises chrétiennes s'est maintenue dans la région : selon ce qu'a dit le mufti de Tozeur à Adrien Berbrugger au milieu du XIx ${ }^{\mathrm{e}}$ siècle, leurs ruines auraient été recouvertes par le sable et l'on en retrouverait parfois par hasard la trace en creusant un puits ou des fondations ${ }^{72}$. Le Sud tunisien a conservé jusqu'à nos jours bien d'autres souvenirs du christianisme. C'est le cas dans le Nafzâwa où le chef-lieu, Kébili, porte encore un nom chrétien, issu du latin capella/chapelle ${ }^{73}$, mais surtout dans le Djérid.

69. X. de Planhol, op. cit., p. 201. Mawlâ Ahmad, op. cit., p. 290 s'indigne de la cynophagie et de la vente d'excréments pratiquées par les habitants de Tozeur. À nouveau, il reprend al-Tidjânî, op. cit., p. 160.

70. Le comte A. du Paty de Clam, Fastes chronologiques de Tôzeur, Paris, Augustin Challamel, 1890, p. 27, note pour l'année 1378 que Tozeur compte encore des chrétiens. E. Savage, op. cit., p. 109, estime qu'un dialecte latin nord-africain était encore parlé au XIV ${ }^{\mathrm{e}}$ siècle dans le Nafzâwa. Sur une carte retraçant la disparition du christianisme, X. de Planhol, op. cit., p. 197, indique avec un point d'interrogation que des chrétiens auraient pu subsister jusqu'au $\mathrm{XVI}^{\mathrm{e}}$ siècle dans le Nafzâwa.

71. Ibn al-Shabbât, trad. dans H.R. Idris, « La vie intellectuelle», p. 105. Il est repris par al-Tidjânî, op. cit., p. 162 puis par Mawlâ Aḥmad, op. cit., p. 292.

72. Adrien Berbrugger, «Itinéraires archéologiques en Tunisie», Revue Africaine, III (1858-1859), p. 20, qui se base sur l'interprétation du texte de Mawlâ Aḥmad.

73. T. Lewicki, « Une langue romane oubliée », p. 460-461. 
Le terme Afâriqa est toujours utilisé dans la région de Tozeur pour désigner les éléments de l'ancienne population qui s'exprimaient en latin ${ }^{74}$. Au début du $\mathrm{xx}^{\mathrm{e}}$ siècle, des coutumes byzantines relatives au baptême y sont encore appliquées, transposées à l'islam, lors des cérémonies de circoncision : la mère ou le parent le plus proche du circoncis trace une croix sur sa poitrine puis sur son dos, le doigt trempé dans de l'eau safranée ${ }^{75}$. La légende connue dans l'Occident musulman sous le nom de «sept dormants d'Éphèse » est très présente dans le Sud tunisien : suite à la persécution ordonnée par l'empereur romain Dèce (249-251), sept jeunes chrétiens se sont réfugiés dans une caverne et y ont été emmurés vivants. Deux siècles plus tard, ils se sont réveillés et ont témoigné de l'époque de la persécution ${ }^{76}$. Si le Coran a largement contribué à répandre cette histoire par la sourate XVIII « la caverne », elle était célèbre avant la conquête arabe et Henri Basset estime qu'au Maroc où elle est très présente, elle a pu parvenir à l'époque du christianisme ${ }^{77}$. Dans le Sud tunisien, il existe plusieurs grottes des sept dormants à Midès, dans le djebel Demmer et dans la région de Tozeur qui en compte au moins trois ${ }^{78}$. La tradition la plus vive liée aux gens de la caverne semble être celle conservée à Chenini de Tataouine, où l'on voit encore au pied de la mosquée ancienne de mystérieuses tombes longues de plus de quatre mètres. Selon la légende locale, il y avait à cet endroit un village de chrétiens, peut-être des donatistes, de très

74. Lucienne Saada, Éléments de description du parler arabe de Tozeur, Paris, Geuthner, 1984, p. 104.

75. J. Oliver Asín, «En torno a las orígenes de Castilla : su toponimia en relación con los árabes y los beréberes », Al-Andalus, XXXVIII (1973), p. 370.

76. François Jourdan, La tradition des sept dormants, Paris, Maisonneuve et Larose, 1983, p. 13-15.

77. Henri Basset, Le culte des grottes au Maroc, Alger, Jules Carbonel, 1920, p. 28.

78. Y. Moubarac, «Le culte liturgique et populaire des VII dormants martyrs d'Éphèse », Studia Missionalia, Rome, 1961, p. 40 et p. 42 ; F. Jourdan, op. cit., p. 147-148. La caverne la plus connue semble être celle située dans la montagne qui domine Taqyûs ; elle est décrite notamment par Mawlâ Aḥmad, op. cit., p. 286-287, et par A. Berbrugger, op. cit., p. 17. 
grande taille, qui ont adopté l'islam et sont morts juste après leur conversion ${ }^{79}$.

\section{LA DISPARITION DES CHRÉTIENS DU SUD TUNISIEN}

La plupart des historiens contemporains expliquent la disparition du christianisme maghrébin par la fuite des élites au cours des exodes successifs, l'absence d'un clergé organisé et la méconnaissance progressive de la liturgie, liée à la disparition de l'usage du latin ${ }^{80}$. Dès lors, pour reprendre la formule de Mohamed Talbi, le christianisme africain « s'étiola, dépérit, et finalement s'éteignit comme une lampe privée d'huile (...) parce qu'il ne sut, ou ne put, trouver en son sein les ressources intellectuelles indispensables à sa survie ${ }^{81}$. Il faut noter que les chrétiens des oasis ont peut-être conservé la pratique du latin plus longtemps qu'ailleurs, puisque son usage est encore attesté $\mathrm{au} \mathrm{XII}^{\mathrm{e}}$ siècle à Gafsa, avec laquelle ils entretiennent de constantes relations ; de plus, la situation excentrée des oasis a peutêtre découragé l'élite de se joindre aux exodes. D'autres historiens insistent sur une raison pratique pour justifier la fin du christianisme local : l'absence d'épiscopat ne permettrait pas aux chrétiens de se maintenir comme tels car, l'indispensable sacrement du baptême ne pouvant avoir lieu qu'avec la consécration de l'évêque, les chrétiens

79. Zygmunt Komorowski, « Contribution à l'étude des traditions culturelles du Nord-Est maghrébin (les confins algéro-tunisiens) », Africana Bulletin, XXVII (1978), p. 23. Voir une autre interprétation de la légende dans l'Encyclopédie berbère, III, Aix-en-Provence, Édisud, 1986, p. 319.

80. Puisqu'il n'y eut manifestement pas de traduction de la Bible et de la liturgie en berbère, les chrétiens maghrébins se sont retrouvés dépourvus de littérature religieuse dans une langue par eux compréhensible alors qu'en Orient, le christianisme s'est adapté aux langues locales comme le copte ou le syriaque. Ramón Lourido Diáz et Henri Teissier, El cristianismo en el norte de África, Madrid, Editorial MAPFRE, 1993, p. 52.

81. M. Talbi, op. cit., p. 330-331. Ch.-E. Dufourcq, op. cit., p. 220, fait le lien entre la voie du secret/kitmân qu'ont dû adopter la plupart des ibadites pour subsister et la discrétion à laquelle ont été également contraints les chrétiens depuis l'apparition de l'islam. Il suppose qu'au contact des ibadites, les chrétiens ont pris l'habitude de dissimuler leurs croyances et qu'ainsi le christianisme « aurait disparu à la longue, enseveli dans son secret ». 
auraient donc dû devenir musulmans pour conserver un statut dans la société 82 . Il est bien évident cependant que les chrétiens des oasis ont pu s'organiser pendant plusieurs siècles sans jouir de la présence d'un évêque. Ils se sont sans doute contentés d'un chef civil désigné par eux et reconnu par le pouvoir, comme c'était le cas en Espagne ${ }^{83}$.

Les chrétiens et les ibadites s'éteignent à une époque sensiblement identique. Nous avons étudié ailleurs dans quelles circonstances les ibadites ont disparu du Djérid et du Nafzâwa ${ }^{84}$. À l'exception des luttes qui opposaient les différents groupes ibadites, les deux raisons principales qui ont provoqué leur extinction peuvent manifestement expliquer la disparition des derniers chrétiens. D'une part, la guerre violente qui a opposé les Almohades aux Banû Ghâniya a eu pour conséquence la destruction ou l'abandon de plusieurs villages, tant dans le Djérid que dans le Nafzâwa. L'exemple le plus remarquable en est l'ancien évêché de Turris Tamalleni, Turra, ruiné en 601/ 1204-1205 ${ }^{85}$. Ce long conflit nuit fortement à l'économie de la région : sa prédominance commerciale diminue au profit de villes situées plus profondément dans le désert, où migrent sans doute de nombreux oasiens. D'autre part, après la conquête almohade, les ibadites subissent une très forte pression de la part des sunnites : leur nombre ne cesse de croître dans la région et de nombreux juristes malékites viennent en renfort pour convertir les hérétiques. Dans le même temps, le maraboutisme remporte un franc succès, notamment à Nefta grâce au charismatique Sîdî Bû 'Alî. En quelques décennies, face à ces multiples agressions, les communautés ibadites des oasis s'éteignent. Les dernières preuves indiscutables de leur présence datent du milieu du XIII $^{\mathrm{e}}$ siècle. Les épreuves traversées par les

82. Mikel De Epalza, « Notes de sociologie religieuse médiévale : la disparition du christianisme au Maghreb et à Al-Andalus », in Mélanges offerts à Mohamed Talbi, Tunis, Publications de la Faculté des Lettres de la Manouba, 1993, p. 71-73.

83. Ch. Courtois, op. cit., p. 116-119. Il souligne, p. 217, que la lettre de Grégoire VII déplorant l'absence de trois évêques africains prouve qu'il y avait des communautés dépourvues d'évêques.

84. V. Prevost, op. cit., p. 263-298 et p. 317-323.

85. Al-Tidjânî, op. cit., p. 147 et p. 356 ; Ibn Khaldûn, op. cit., éd. VI, p. 231 et trad. II, p. 99. 
ibadites ont évidemment frappé les chrétiens, soudain confrontés à une active propagande religieuse, alors qu'ils vivaient leur foi sans contrainte depuis des siècles. Le sort de ces deux communautés nous paraît intimement lié : leur entente a certainement contribué à ce que les chrétiens puissent se maintenir aussi longtemps. Il est probable que les ibadites ont majoritairement choisi, plutôt que de se convertir, de gagner les régions où leurs coreligionnaires vivaient sans être inquiétés, comme Djerba ou le Mzab. De même, les derniers chrétiens ont sans doute rejoint les villes où «l'église immigrée » s'était imposée, leur assurant protection et encadrement religieux.

Nous pensons donc, après avoir démontré le caractère très hypothétique des arguments fournis par Ibn Khaldûn, que les chrétiens des oasis ont disparu vers le milieu du $\mathrm{XIII}^{\mathrm{e}}$ siècle. Cette datation s'accorde parfaitement avec le témoignage d'Ibn al-Shabbât qui note, dans la seconde moitié de ce siècle, des emplacements d'églises en ruine mais ne signale plus de chrétiens. Bien qu'il faille reconsidérer l'exceptionnelle longévité qu'on leur a généralement prêtée, les communautés chrétiennes locales du Djérid et du Nafzâwa semblent bien avoir été les dernières communautés d'Afrique du Nord à se maintenir sans apport extérieur, ce qui peut certainement s'expliquer par leur présence en terre ibadite.

8 hameau de la Taillette

7911 Frasnes-lez-Anvaing

Belgique

virginie.prevost@skynet.be 